\title{
Head and neck lymphedema: what is the physical therapy approach? A literature review
}

\section{Linfedema de cabeça e pescoço: qual a abordagem da fisioterapia? Uma revisão de literatura}

\author{
Lunara Basqueroto Della Justina ${ }^{[\mathrm{a}]}$, Mirella Dias ${ }^{[\mathrm{b}] *}$ \\ [a] Universidade do Planalto Catarinense (UNIPLAC), Lages, SC, Brazil \\ [b] Universidade do Sul de Santa Catarina (UNISUL), Palhoça, SC, Brazil
}

\begin{abstract}
Introduction: Head and neck lymphedema is considered a chronic and complex complication with potential to cause physical, functional, emotional and social impairment. Objective: To identify the approaches to physical therapy used to treat head and neck cancer-related lymphedema. Method: A bibliographic search was conducted in February and March 2012 in books and electronic databases, LILACS, MEDLINE, SCIELO, Cochrane, PEDro, and BDTD using the following keywords: lymphedema, treatment, head and neck cancer, and physical therapy connected by the Boolean operator AND without a specific time frame. Results and discussion: Early diagnosis and assessment is key to properly managing and effectively treating lymphedema. Diagnosis is reached through clinical history and physical assessment by measuring the distance between two anatomical landmarks, circumference measures, and lymphedema rating scales. Complex decongestive therapy, which includes manual lymph drainage, compressive bandaging, kinesiotherapy and skin care, is the technique most frequently used and currently considered to be the gold standard. Conclusions: No consensus is reported in the literature in regard to a standard procedure to assess and treat head and neck cancer-related lymphedema. Assessments and treatments described in the literature are mainly restricted to the limbs; therefore, further studies are needed to support effective clinical actions in the physical therapy approach to this condition.
\end{abstract}

Keywords: Lymphedema. Head and neck neoplasms. Physical therapy modalities. Therapeutics. 


\section{Resumo}

Introdução: O linfedema de cabeça e pescoço é considerado uma complicação crônica e complexa que pode provocar prejuízos físicos, funcionais, emocionais e sociais importantes. Objetivo: Identificar as abordagens fisioterapêuticas utilizadas no linfedema pós-tratamento de câncer de cabeça e pescoço. Método: Para o delineamento dessa revisão, foi realizado levantamento bibliográfico nos meses de fevereiro e março de 2012, em livros e nas bases de dados eletrônicas LILACS, MEDLINE, SCIELO, Cochrane, PEDro, BDTD utilizando as palavras-chave: linfedema, tratamento, câncer de cabeça e pescoço, fisioterapia ligadas pelo operador boleano AND, sem estabelecer data limite para a publicação. Resultados e discussão: $O$ diagnóstico precoce e a avaliação são fundamentais para o manejo adequado e tratamento efetivo do linfedema. O diagnóstico é realizado através da história clínica e do exame físico pela medida da distância entre dois pontos anatômicos, das medidas de circunferência e escalas de intensidade do linfedema. A fisioterapia complexa descongestiva ou linfoterapia que inclue: drenagem linfática manual, bandagem compressiva, cinesioterapia e cuidados com a pele, é a técnica mais utilizada na intervenção do linfedema, considerada padrão ouro atualmente. Conclusões: De acordo com a literatura revisada, não há consenso sobre o procedimento padrão para avaliação e tratamento do linfedema após o câncer de cabeça e pescoço. A avaliação e o tratamento para linfedema descritos na literatura estão restritos, principalmente, a membros, sendo assim, novos estudos devem ser realizados a fim de subsidiar ações clínicas efetivas na abordagem fisioterapêtica desta sequela.

Palavras-chave: Linfedema. Neoplasias de cabeça e pescoço. Modalidades de fisioterapia. Tratamento.

\section{Introduction}

Estimates from the National Cancer Institute of Brazil - INCA (2011) indicate an incidence of approximately 520,000 cases of cancer in 2012 and 2013 in Brazil. Of these, 14,170 are new cases of oral cancer and 6,110 are new cases of laryngeal cancer (1). These two types of cancer are part of the group of malignancies of the head and neck (2).

Malignant neoplasms of the head and neck represented by tumors located in the upper aero-digestive tract present significant morbidity and mortality (3). Because it is in an anatomically complex area, head and neck cancer can lead to significant changes in vital structures, resulting in aesthetic and functional sequelae, especially in the face, temporo-mandibular joint, shoulder girdle and lungs $(4,5)$.

The therapeutic methods used to treat head and neck neoplasms include surgical resection, radiotherapy, and chemotherapy, or a combination of these $(4,5,6)$. Even though many of these treatments are effective in eradicating the tumor and/ or generate better results in regard to survival, local control and preservation of function, these interventions usually involve co-morbidities (5). The followup of patients after cancer treatment is important because there may be some after-effects, such as lymphedema $(7,8,9)$.
Head and neck lymphedema that results from therapies used in the treatment of head and neck cancer is considered a chronic and complex complication that manifests as a feeling of heaviness or tightness and permanent discomfort in the affected area; visible swallowing may or may not exist (8). It may, however, become evident and result in important physical, functional (8, $10)$, emotional and social impairment, negatively impacting the quality of life of these individuals $(11,12)$.

Complex decongestive therapy, which includes manual lymph drainage, compressive bandaging or elastic bandages, kinesiotherapy, and skin care, is currently acknowledged as the most efficacious therapeutic method to treat lymphedema (13).

Given the need for further clarification regarding approaches to physical therapy in the treatment of lymphedema for patients with head and neck cancer, and also due to a lack of scientific studies addressing the topic, this review's aim was to identify the physical therapy approaches used to treat head and neck cancer-related lymphedema.

\section{Method}

A bibliographic search was performed in February and March 2012 in books and in electronic databases (LILACS, MEDLINE, SCIELO, Cochrane, PEDro) to 
identify publications addressing the topic using the keywords lymphedema, treatment, head and neck neoplasms, and physical therapy and their equivalent in Portuguese and Spanish, connected by the Boolean operator AND, without establishing a time frame.

A sample from the result of the bibliographic search using this strategy was selected using the following inclusion criteria: full texts with no restriction for study design or time frame; written in English, Portuguese, or Spanish; target population being adults; and studies presenting information concerning the topic under study. Studies identified in more than one database were considered only once. Analysis of papers included reading titles, abstracts and full texts after selection.

The search resulted in 40 studies. After applying inclusion criteria and disregarding repeated papers, a total of six studies were ultimately included. Table 1 presents the characteristics of the studies included in the review with respective physical therapy approaches used to treat head and neck cancer-related lymphedema.

Therefore, the studies selected were organized in order to clarify the general aspects of head and neck lymphedema, the instruments and techniques used to measure head and neck lymphedema in the physical therapy approach and finally, the physical therapy procedures used for individuals with head and neck lymphedema.

\section{Results and Discussion}

General aspects of head and neck lymphedema

Head and neck lymphedema, one of the consequences of head and neck cancer treatment, occurs due to a dysfunction in cervicofacial lymphatic drainage that is caused by surgical procedures in which some structures are removed, such as the neck lymph nodes, and due to radiotherapy applied to the area, which predisposes the patient to the development of lymphedema $(7,8,14,15)$.

Lymphedema, considered a chronic and progressive pathological condition, involves excess interstitial fluid with high protein concentration that originates from an inefficient lymphatic system. Lymphedema develops due to an imbalance between lymphatic demand and the system's ability to drain the lymph; that is, drainage ability is impaired due to the destruction of or an obstruction in the lymphatic route. Hence, as a consequence, organs and tissues are compressed, leading to pain and functional changes. In addition to physical changes, the lymphedema can cause psychological and social problems accruing from aesthetic changes, affecting self-esteem and social acceptability and considerably reducing patient quality of life (15 - 17).

Lymphedema may manifest in patients with head and neck cancer as visible edema in the face and neck area with alterations in the skin's mechanical properties, especially elasticity and viscosity, and sensory changes $(18,19)$. Additionally, it may affect aerodigestive routes, such as in the oral cavity (tongue), pharynx and larynx (19 - 21). Impairment in these areas may affect communication, feeding, breathing, in some cases even impeding walking if sight is impaired. Reduced amplitude of cervical movement is common, as well as dysfunctions in the shoulder girdle (18 - 21).

Most patients with head and neck cancer are diagnosed in the advanced stages of the disease (4). The late diagnosis of these neoplasms is related to a worse prognosis, raising the likelihood of sequelae and deformities. When a head and neck cancer diagnosis is delayed, the expected outcome is worse, with more invasive and mutilating therapeutic interventions that affect the lymphatic system and increase the risk of lymphedema $(18,22)$.

The presence of lymphedema among patients after head and neck cancer treatment is usually neglected and under-recognized; it is less perceived than lymphedema of the extremities (8). The overall prevalence of lymphedema among head and neck cancer patients ranges from $12 \%$ and $75 \%(9,14,22)$. This discrepancy may be explained by a lack of a standard diagnosis and universal assessment criteria, as well as differences among the therapeutic procedures used to treat this type of cancer $(7,9,22)$.

Deng et al (9) conducted a study in the United States to verify the prevalence of lymphedema in a sample composed of 81 patients after head and neck cancer treatment. A total of $75.3 \%$ of the patients presented lymphedema. The study reports a prevalence of external lymphedema, internal lymphedema, and combined lymphedema (concomitantly internal and external lymphedema) with a prevalence of $9.8 \%, 39.9 \%$ and $50.8 \%$, respectively. 


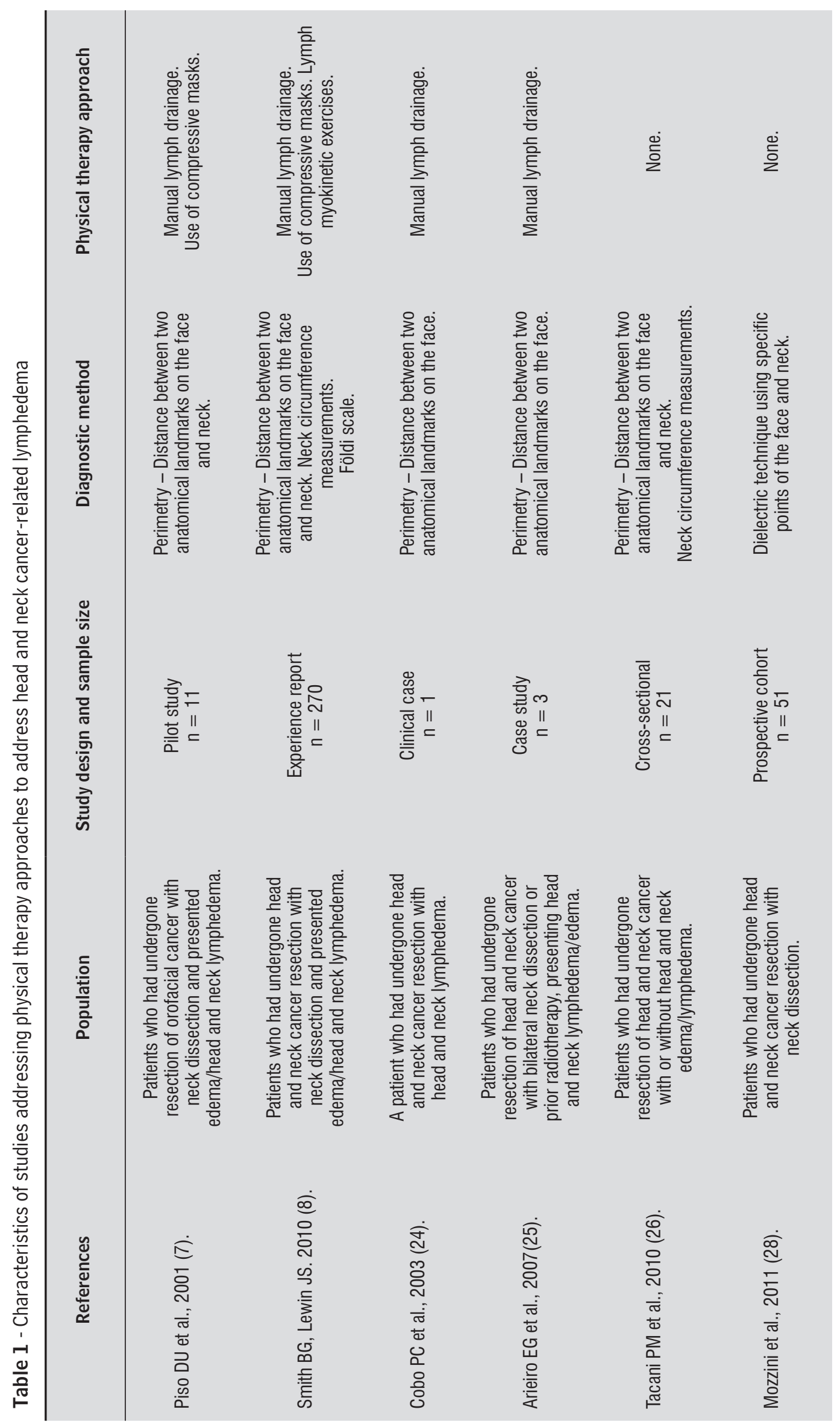


Instruments and techniques used to assess head and neck lymphedema

An early diagnosis and assessment to verify its physiopathology is essential for the appropriate management and effective treatment of lymphedema. Among the techniques described in the literature, diagnosis is reached through examination of clinical history and physical assessment. The quantitative assessment of lymphedema includes measuring skin folds, perimetry, compression techniques, and water displacement techniques. Most of these techniques, considered to be indirect methods, are related to the assessment of limbs and are difficult to apply to the head and neck area because they are reproduced through volume and circumference measurement. In addition to these techniques, other devices can be used, such as image exams: ultrasound, magnetic resonance and computed tomography. The high cost of image techniques, however, hinders their use in the routine assessment of lymphedema (7, 9, 22 - 24).

To date, there is no standardized technique to measure head and neck lymphedema. The methods identified in the literature $(7,8,24$ - 28) include the distance between two anatomical landmarks, circumference measured with a tape and the dielectric technique. Piso et al (7) measured lymphedema after surgical resection of the head and neck using the following: angle of jaw to the inner corner of eye; angle of jaw to the outer corner of eye; tip of chin to the outer corner of eye; and angle of jaw to the tip of chin. Cobo et al (24) verified facial lymphedema through the mandibular angle as passing by the chin, mandibular angles as passing by the mid-line of the oral commissures and earlobe passing through the upper lip.

The measurements performed by Arieiro et al (25) to assess lymphedema in patients who had undergone head and neck cancer surgery resection associated with bilateral neck dissection or prior radiotherapy involved the following anatomical landmarks: angle of the jaw to the outer corner of the eye; angle of the jaw to the inner corner of the eye; tip of chin to the outer corner of eye; tip of chin to the jaw angle; earlobe to upper lip area; jaw angles by the midline of the oral commissures; angle of mouth to earlobe; tip of chin to earlobe; and tip of chin to nasal sidewall.

Tacani et al (26) proposed a protocol to assess head and neck lymphedema developed with 10 measures of distances between anatomical landmarks comprising the face and neck region and neck circumference: angle of jaw to the outer corner of eye; angle of jaw to the inner corner of eye; jaw angles through the midline of the oral commissures; earlobe through upper lip region; earlobe to tip of chin; earlobe to lip angle; earlobe through submental area; tip of chin to the outer corner of eye; tip of chin to the jaw angle; tip of chin to the nasal sidewall; neck circumference, eight centimeters below earlobe. According to the results reported by Tacani et al (26), the protocol they proposed was accurate, and presented inter- and intra-reproducibility, enabling its used in clinical practice.

Smith \& Lewin (8) described a protocol to assess lymphedema in patients with head and neck cancer that is used in the M. D. Anderson Cancer Center (MDACC), University of Texas, USA. The protocol consists of two measures of head circumference (diagonal and submental); three measures of neck circumference (bottom, middle and upper neck) and distance between anatomical landmarks. The following anatomical landmarks were part of the protocol: distance between jaw angles; distance between landmarks located in the tragus; tragus to the tip of chin; tragus to the lip angle; angle of jaw to the nose sidewall; angle of jaw to the eye inner corner; angle of jaw to the eye outer corner; tip of chin to the eye inner corner; tip of chin to the angle of jaw.

The dielectric method, considered to be noninvasive, reproducible and easy to apply, is used to measure local water alterations in skin and subcutaneous fat in any area of the body. Central and peripheral edemas, fluid retention and swollen tissue can be measured. The dielectric technique consists of an electromagnetic high-frequency wave generated by the control unit and transmitted through a probe placed under the skin and then transmitted into the subcutaneous tissue, where energy absorption occurs by water enabling a localized, exact, quantitative and objective assessment of the fluid volume existing below the probe (27).

Mozzini (28) conducted a study using the dielectric technique to measure edema in specific points located in the face and neck of individuals who had undergone neck dissection with or without resection of the internal jugular vein due to malignant neoplasms in the head and neck area. The author used the following measurement landmarks: center of the right lower eyelid; center of the left lower eyelid; midpoint between the nasal sidewall and the tragus to the left; midpoint between the nasal sidewall and the tragus to the right; starting from the midpoint 
between the nasal sidewall and the tragus to the left to the lower edge of the left jaw; starting from midpoint of the nasal sidewall and tragus to the right to the bottom edge of mandible; chin; area of the hyoid bone; starting from the midpoint between the nasal sidewall and tragus to the right to align with the hyoid bone to the right; starting from the midpoint between the nasal sidewall and tragus to the left to align with the hyoid bone to the left. The areas most frequently affected by edema were the mandibular and neck areas.

In addition to quantitative assessment, a lymphedema can also be classified in regard to its intensity. A commonly used scale, Földi's scale, was based on the experience of its authors who treated more than 100,000 patients with lymphedema. The scale, which classifies lymphedema into phases, is not specific for patients with head and neck cancer-related lymphedema but can be used to understand the physiopathological process and consequent clinical changes (13) (Table 2).

Table 2 - Classification and staging of lymphedema

\begin{tabular}{ll}
\hline & Lymphedema is reversible with a small increase \\
in the interstitial lymph and a certain stasis in the \\
Phase I \\
to lymphatic vessels. Reduces easily in response \\
Lymphedema is irreversible, presenting fibrosis of \\
the interstitial fluid in some parts of the affected \\
area and increased skin firmness, with a certain \\
degree of collector- and capillary-stagnant lymph. \\
A therapeutic approach is required. \\
Shase II \\
Severe lymphedema with a high level of \\
static lymph and severe stagnation of lymph \\
in vessels and capillaries, the affected area \\
considerably increases in volume; skin becomes \\
dry, brittle, with dark and orange peel aspect, \\
becoming more vulnerable to infections such \\
as erysipelas, lymphangitis, while the region \\
affected by lymphedema is deformed.
\end{tabular}

Note: Source: Camargo and Marx, 2000
Smith \& Lewin (8) report the use of the MDACC scale, which was developed by the M.D. Anderson Cancer Center, based on the Földi's scale, to classify head and neck cancer-related lymphedema.

Assessment is essential for the effective treatment of lymphedema, however, most studies addressing the topic report that the instruments used to measure head and neck cancer-related lymphedema are insufficient because the procedures used to treat this type of cancer are mutilating and involve the resection of lymph nodes and other structures, reducing tissue volume in the compromised area, hindering the effective use of circumferential techniques or verification of the distance between two landmarks $(7,9,18,22,24,25)$.

\section{Physical therapy approaches used in the treatment of head and neck lymphedema}

Currently, complex decongestive therapy stands out among lymphedema-related interventions and is composed of two phases (intensive and maintenance) that including the following procedures: manual lymph drainage, compression bandaging or elastic bandage, lymph myokinetic exercises and skin care (13).

Manual lymph drainage is a technique commonly used by physical therapists to treat lymphedema, with the objective to drain excess interstitial fluid, fluid in tissue and vessels, removing substances that result from cell metabolism and maintaining water balance in interstitial spaces. This technique is composed of slow, rhythmic and gentle strokes that follow the direction of the physiological lymph drainage. It is initiated with evacuation, a process intended to transport and remove the lymph, followed by collection, which absorbs edema at the level of initial lymph vessels in the area compromised by lymphedema $(13,15)$.

Compression bandaging works through modifying the venous capillary, lymphatic and tissue dynamics, increasing the efficacy of muscle and joint pumping. It is used to maintain and increase the effects of manual lymphatic drainage (13).

Kinesiotherapy applied through lymph myokinetic exercise is aimed to stimulate muscle activity and recover joint amplitude. Skin care prevents infections and improves skin condition (13).

The studies addressing physical therapy in the treatment of head and neck lymphedema investigate the efficacy of manual lymph drainage $(24,25)$, as well as its efficacy associated with compressive bandaging $(7,8)$. 
The treatment of head and neck lymphedema is more complex than the treatment provided to lymphedema in the upper limbs caused by breast cancer. Patients affected by head and neck lymphedema may present external or internal lymphedema or even a combination of both (9).

According to studies, external lymphedema can be treated with manual lymph drainage and compressive bandage masks; however, the efficacy of these resources for the treatment of internal lymphedema is unknown. Additionally, because the lymphedema is located on the face and neck, compressive bandage masks are not always well-tolerated by patients and usually need to be customized, that is, build according to the anatomy of each patient's head and neck. Additionally, if these masks are misused, they may interfere with blood circulation in the area (7-9).

Piso et al (7) investigated the efficacy of manual lymph drainage associated with the use of compressive bandage masks to treat head and neck lymphedema. Eleven patients received 10 sessions of manual lymphatic drainage, performed according to the Vodder method, which lasted between 30 and 60 minutes. The patients used the mask for approximately four weeks. The authors concluded that the use of manual lymph drainage associated with compressive bandage masks is efficacious to reduce lymphedema in this area.

Other studies have also investigated the efficacy of manual lymph drainage to treat head and neck cancer-related lymphedema. Cobo et al (24) verified the efficacy of manual lymph drainage in a case study of face lymphedema. They verified that 25 sessions of 45 minutes each, on average, was efficacious. The final assessment using the distance between anatomical landmarks revealed that the measures were decreased and facial lymphedema was reduced. Arieiro et al (25) studied three inpatients who developed lymphedema after head and neck cancer surgery. The study protocol was composed of ten 30-minute sessions of manual lymph drainage applied on each hemiface, based on Camargo and Marx's method. The lymphedema was measured before and after the technique was applied and analysis of results suggested that manual lymph drainage was efficacious in the sample under study to reduce facial lymphedema after head and neck cancer surgery.

A treatment developed by the MD Anderson Cancer Center and used for patients with head and neck cancer-related lymphedema was described in the study conducted by Smith and Lewin (8). The treatment combines outpatient treatment and maintenance at home using manual lymph drainage, compressive bandage masks and lymph myokinetics. This model of treatment is based on the experience of treating more than 270 patients with head and neck cancer-related lymphedema. The authors report the need for further clarification and scientific evidence regarding the procedures to treat head and neck lymphedema; however, as suggested by their experience, the model developed by the MD Anderson Cancer Center improves patients' condition, when comparing patients who adhered to the treatment with those who did not.

The limitations of this study include the limited number of scientific studies addressing this topic and a lack of methodological rigor among the studies found.

\section{Conclusions}

This literature review suggests that the physical therapy approach to the treatment of lymphedema in head and neck cancer-related lymphedema is essential to preventing and minimizing physical, functional, emotional and social impairment resulting from this complication.

The literature shows there is no consensus regarding a standard procedure to assess and treat head and neck lymphedema. Assessments and treatments provided for lymphedema as described in the literature are mainly restricted to treatment of the limbs. The studies addressed in this review reinforce the importance of assessing conditions necessary for treatment of head and neck lymphedema to be effective and suggest the employment of less expensive and measurements and instruments that are easy-to-apply, such as the distance between landmarks, circumference measurements and rating scales commonly used in clinical practice. In regard to the therapeutic approach to lymphedema, complex decongestive therapy is the modality that has the firmest scientific support, while manual lymph drainage is the treatment most frequently used to treat head and neck lymphedema and is considered beneficial to preventing and minimizing the consequences of this condition.

Further studies with optimized methodological designs should be conducted to support safe, appropriate and effective clinical actions in physical therapy approaches to head and neck lymphedema. 


\section{References}

1. Ministério da Saúde. Instituto Nacional de Câncer. Estimativa 2012: incidência de câncer no Brasil. Rio de Janeiro: INCA; 2011.

2. Dobrossy L. Epidemiology of head and neck cancer: magnitude of the problem. Cancer and Metastasis Rev. 2005; 24: 9-17.

3. Argiris A, Karamouzis MV, Raben D, Ferris RL. Head and neck cancer. Lancet. 2008; 371: 1695-709.

4. Marur S, Forastiere A. Head and neck cancer: chaging epidemiology, diagnosis and treatment. Mayo Clin Proc. 2008; 83: 489-501.

5. Sigler BA. Nursing care for head and neck tumor patients. In: Thawley SE, Panje WR, Batsakik JG, Lindberg RD. Comprehensive management of head and neck tumors. 2. ed. Philadelphia: Saunders; 1999.v.1, p.59-78.

6. Prince MEP, Ailles LE. Cancer stem cells in head and neck squamous cell cancer. J Clin Oncol. 2008; 26: 2871-5.

7. Piso DU, Eckardt A, Liebermann A, Gutenbrunner C, Schäfer P, Gehrke A. Early rehabilitation of head-neck edema after curative surgery for orofacial tumors. Am J Phys Med Rehabil. 2001; 80: 261-9.

8. Smith BG, Lewin JS. Lymphedema management in head and neck cancer. Curr Opin Otoryngol Head Neck Surg. 2010; 18: 153-8.

9. Deng J, Ridner SH, Dietrich MS, Wells N, Wallston KA, Sinard RJ, et al. prevalence of secondary lymphedema in patients with head and neck cancer. J Paim Symptom Manage. 2012; 43: 244-52.

10. Micke O, Bruns F, Mücke R, Schäfer U, Glatzel M, DeVries AF, et al. Selenium in the treatment of radiation-associated secondary lymphedema. Int J Radiat Oncol Biol Phys. 2003; 56: 40-9.

11. Penner JL. Psychosocial care of patients with head and neck cancer. Semin Oncol Nurs. 2009; 25: 231-41.

12. Murphy BA, Gilbert J, Ridner SH. Systemic and global toxicities of head and neck treatment. Expert Rev Anticancer Ther. 2007;7:1043-53.

13. Camargo MC, Marx AG. Reabilitação física no câncer de mama. São Paulo: Roca; 2000.
14. Büntzel J, Glatzel M, Mücke R, Micke O, Bruns F. Influence of amifostine on late radiation-toxicity in head and neck cancer: a follow-up study. Anticancer Res. 2007; 27: 1953-56.

15. Leduc A, Leduc O. Drenagem linfática: teoria e prática. 3. ed. São Paulo: Manole; 2008.

16. Mortimer PS. The pathophysiology of lymphedema. Cancer. 1998; 83: 2798-2802.

17. Rockson SG, Miller LT, Senie R, Brennan MJ, CasleySmith JR, Földi E, et al. American Cancer Society Lymphedema Workshop.Workgroup III: Diagnosis and management of lymphedema. Cancer. 1998; 83(12 Supl):2882-5.

18. Zimmermann T, Leonhardt H, Kersting S, Albrecht S, Range U, Eckelt U. Reduction of postoperative lymphedema after oral tumor surgery with sodium selenite. Biol Trace Elem Res. 2005; 106: 193-203.

19. Bruns F, Büntzel J, Mücke R, Schönekaes K, Kisters K, Micke O. Selenium in the treatment of head and neck lymphedema. Med Prin Pract. 2004; 13: 185-90.

20. Murphy BA, Gilbert J. Dysphagia in head and neck cancer patients treated with radiation: assessment, sequelae, and rehabilitation. Semin Radiat Oncol. 2009; 19: 35-42.

21. Ridner SH. Lymphedema of the head and neck: an overview. NLN Lymph Link. 2008; 20: 1-3.

22. Chen $\mathrm{MH}$, Chang PM, Chen PM, Tzeng $\mathrm{CH}$, Chu PY, Chang SY, et al. Prolonged facial edema is an indicator of poor prognosis in patients with head and neck squamous cell carcinoma. Support Care Cancer. 2010; 18: 1313-9.

23. International Society of Lymphology. The diagnoses and treatment of peripheral lymphedema. Consensus document of the International Society of Lymphology. Lymphology. 2003; 36:84-91.

24. Cobo PC, Díaz PLM, Molina DR, Garcia EV, Vázquez AS, Fernandez Vega V. Drenaje linfático manual en el linfedema facial. Rehabilitación. 2003; 37: 291-3.

25. Arieiro EG, Machado KS, Lima VP, Tacani RE, Diz AM. A eficácia da drenagem linfática manual no pósoperatório de câncer de cabeça e pescoço. Rev Bras Cir Cabeça Pescoço. 2007; 36: 43-6. 
26. Tacani PM, Santos APR, Poscolere DD, Padilha QCSV, Amatu TKI, Montezello D, et al. Protocolo de avaliação de linfedema de cabeça e pescoço. Rev Bras Cir Cabeça Pescoço. 2010; 39: 126-30.

27. Lahtinen T, Nuutinen J, Alanen E. Dieletric Properties of the skin. Phy Med Biol. 1997; 42:1471-2.

28. Mozzini CB. Edema na face e no pescoço após esvaziamento cervical com ou sem ressecção da veia jugular interna [Thesis]. São Paulo: Faculdade de Medicina da Universidade de São Paulo; 2011.110p.

Received: 05/24/2016

Recebido: 24/05/2016

Approved:05/27/2016

Aprovado: 27/05/2016 
